\title{
Cancer immunotherapy with T-cell targeting cytokines: IL-2 and IL-7
}

\author{
Ji-Hae Kim ${ }^{1}$, Kun-Joo Lee ${ }^{2}$ \& Seung-Woo Lee ${ }^{1,2, *}$ \\ ${ }^{1}$ Department of Life Sciences and ${ }^{2}$ Division of Integrative Biosciences and Biotechnology, Pohang University of Science and Technology \\ (POSTECH), Pohang 37673, Korea
}

Clinical trials have demonstrated that an increased number of effector cells, especially tumor-specific T cells, is positively linked with patients' prognosis. Although the discovery of checkpoint inhibitors (CPIs) has led to encouraging progress in cancer immunotherapy, the lack of either T cells or targets for CPIs is a limitation for patients with poor prognosis. Since interleukin (IL)-2 and IL-7 are cytokines that target many aspects of T-cell responses, they have been used to treat cancers. In this review, we focus on the basic biology of how these cytokines regulate T-cell response and on the clinical trials using the cytokines against cancer. Further, we introduce several recent studies that aim to improve cytokines' biological activities and find the strategy for combination with other therapeutics. [BMB Reports 2021; 54(1): 21-30]

\section{INTRODUCTION}

Active research on cancer immunotherapy has shown that $\mathrm{T}$ cells play the most important role in anti-cancer immunity. To eliminate cancer cells, T-cell responses proceed step by step along the cancer-immunity cycle (1). Initially, tumor antigens need to be properly presented by dendritic cells (DCs) to prime and activate tumor-specific T cells. The activated T cells then move in the tumor bed followed by recognition of cognate antigens. After an encounter with an antigen, the tumor-specific $T$ cell should properly induce effector functions. Finally, if this cycle lasts long enough to keep its optimal condition, patients may be able to avoid cancers.

Indeed, not only $\mathrm{T}$ cells but also almost all types of immune cells can be found within a distinct tumor microenvironment (TME) that differs between individual patients depending on the cancer types, disease progression, and conditions of immunity

*Corresponding author. Tel: +82-54-279-2355; Fax: +82-54-279-0657; E-mail: sw_lee@postech.ac.kr

https://doi.org/10.5483/BMBRep.2021.54.1.257

Received 2 November 2020, Revised 5 December 2020, Accepted 28 December 2020

Keywords: Cancer immunotherapy, Cytokine, IL-2, IL-7, T cells
(2). Nevertheless, meta-analyses of clinical studies have demonstrated that strong tumor infiltration of effector immune cells, especially $\mathrm{CD}^{+}{ }^{+} \mathrm{T}$ cells, are clearly associated with good prognosis and clinical outcomes. The problem is that not all patients have a good immunological status with enough effector T cells. Some clinical data have epidemiologically shown that T-cell counts are highly associated with cancer incidence (3). Furthermore, lymphopenia has been frequently observed in cancer patients with poor prognosis, although it is still not clear whether the lymphopenia is a cause or an effect.

The common cytokine-receptor gamma chain $\left(\gamma_{c}\right)$ cytokines are important regulators of the immune system by exhibiting pleiotropic roles in both innate and adaptive immune cells (4). These cytokines consist of diverse interleukins (ILs): IL-2, IL-4, IL-7, IL-9, IL-15. and IL-21. Among them, IL-2 and IL-7 have been long and widely used for inducing the development and proliferation of T cells. In general, IL-2 acts as a 'stimulus' to induce activation of T-cell responses, whereas IL-7 acts as an 'expander' to increase the number of T cells, which have been more widely used to overcome the lymphopenia derived from chronic viral infections rather than from cancer. In this review, we summarize the biology of the cytokines and their clinical uses against cancer.

\section{BIOLOGY OF IL-2}

IL-2 is a $15.5-\mathrm{kDa}$ glycoprotein that was first identified as a T-cell growth factor in 1976 (5). IL-2 is predominantly produced by activated $\mathrm{CD}^{+}$helper $\mathrm{T}\left(\mathrm{T}_{\mathrm{H}}\right)$ cells in secondary lymphoid organs and to a lesser extent by activated $\mathrm{CD}^{+} \mathrm{T}$ cells, natural killer (NK) cells, natural killer T (NKT) cells, and DCs. IL-2 stimulates downstream signals in target immune cells by binding to the IL-2 receptor (IL-2R) that has either 2 or 3 subunits, including the cytokine-specific IL-2R $\alpha$ (also known as CD25), IL-2R (also known as CD122), and IL-2R (also known as CD132 or more frequently as $\gamma_{c}$ ). IL-2R $\beta$ is shared with IL-15, and $\gamma_{c}$ is shared with IL-4, IL-7, IL-9, IL-15, and IL-21. IL-2R $\beta$ and $\gamma_{c}$ constitute an intermediate-affinity dimeric IL-2R $\beta \gamma$ (dissociation constant $\left(K_{d}\right) \approx 10^{-9} M$ ), whereas all 3 subunits make up a high-affinity trimeric IL-2R $\alpha \beta \gamma\left(K_{d} \approx 10^{-11} M\right)(6)$. Although IL-2R $\alpha$ by itself is also a low-affinity monomeric IL-2R $\left(K_{d} \approx 10^{-8} \mathrm{M}\right)$, it does not induce a signal but seems to support the binding of IL-2R $\beta \gamma$ for

ISSN: 1976-670X (electronic edition)

Copyright (C) 2021 by the The Korean Society for Biochemistry and Molecular Biology

(ㄷ) This is an open-access article distributed under the terms of the Creative Commons Attribution Non-Commercial License (http://creativecommons.org/licenses/by-nc/4.0) which permits unrestricted non-commercial use, distribution, and reproduction in any medium, provided the original work is properly cited. 
IL-2 $(6,7)$. Although the IL-2R $\beta$ is expressed on memory CD8 ${ }^{+}$ $\mathrm{T}$ cells at higher levels than on memory $\mathrm{CD} 4^{+} \mathrm{T}$ cells, these cells are relatively unresponsive to the physiological levels of IL-2, but become sensitive to the high amounts of IL-2 that are generally induced by the administration of exogenous IL-2 (8, 9). The high-affinity trimeric IL-2R $\alpha \beta \gamma$ is predominantly expressed on immunosuppressive $\mathrm{CD}^{+}{ }^{+} \mathrm{Foxp}^{+}{ }^{+}$regulatory $\mathrm{T}$ ( $\mathrm{T}_{\mathrm{REG}}$ ) cells via constitutive expression of IL-2R $\alpha$ at high levels, whereas other T subsets transiently upregulate IL-2R $\alpha$ after activation following T-cell receptor (TCR) stimulation (10).

IL-2 plays a critical role in the regulation of $\mathrm{CD}^{+}{ }^{+} \mathrm{T}$-cell immunity. It promotes polarization and survival of the $T_{H} 1$, $T_{H} 2, T_{H} 9$, and $T_{\text {REG }}$ cells, but inhibits generation of $T_{H} 17$ and follicular helper $\mathrm{T}\left(\mathrm{T}_{\mathrm{FH}}\right)$ cells by regulating STAT5 downstream signaling (11-15). Mice lacking IL-2, IL-2R $\alpha$, or IL-2R $\beta$ develop systemic autoimmunity and enlargement of peripheral lymphoid organs associated with the polyclonal expansions of $\mathrm{T}$ and $\mathrm{B}$ cells (16-18). The autoimmune disorders can be prevented by the adoptive transfer of $\mathrm{T}_{\text {REG }}$ cells, suggesting that IL-2 signaling contributes greatly to the immune regulation of $T_{\text {REG }}$ cells (19, 20). Indeed, IL-2 signaling is essential for the homeostasis of $\mathrm{T}_{\mathrm{REG}}$ cells but not for the early development and suppressor function of the cells (21). IL-2 also controls the differentiation and expansion of $\mathrm{CD}^{+} \mathrm{T}$ cells. After TCR stimulation, antigenspecific $\mathrm{CD} 8^{+} \mathrm{T}$ cells rapidly upregulate IL-2R $\alpha$ expression within 3 days and then become effector $\mathrm{T}$ cells expressing different levels of IL-2R $\alpha$ coupled with the reciprocal signal strength of IL-2. Whereas cells receiving strong IL-2 signaling differentiate toward short-lived terminal-effector cells mediated by the induction of B-lymphocyte-induced maturation protein 1 (BLIMP1), cells receiving low IL-2 signaling upregulate IL-7R $\alpha$ (also known as CD127) and CD62L expressions displaying a phenotype of long-lived memory cells $(22,23)$. Persistent stimulation of TCR with IL-2 signals not only increases cytotoxic activities of activated $\mathrm{CD} 8{ }^{+} \mathrm{T}$ cells but also promotes apoptosis of the cells by activation-induced cell death via the expression of the death receptor FAS (also known as CD95) and its ligand, CD95L (24). This process is very important in maintaining the self-tolerance of overactive T cells. Since IL-2 plays the pleiotropic roles in T-cell homeostasis, the administration of recombinant IL-2 was evaluated in several clinical trials for the treatment of cancers in diverse dose ranges and therapeutic schedules.

\section{THERAPEUTIC APPROACHES OF IL-2 AGAINST CANCER}

IL-2 immunotherapy was evaluated in several clinical trials because of its ability to expand and activate cytotoxic effector cells. The administration of high-dose IL-2 in bolus doses achieved effective objective regressions of metastatic cancers; however, severe side effects were seen in patients, including fluid retention, organ dysfunction, hypotension, and treatment-related deaths. The toxicities were directly related to the dose of IL-2 administered (25-27). In 255 patients with metastatic renal-cell carcinoma (mRCC), IL-2 therapy achieved $14 \%$ of overall objective response rate (ORR) with 5\% complete responses (CRs) and 9\% partial responses (PRs). The median response duration of partial responders was 19 months. Although the severe treatment-associated toxicities were still observed in the patients, the U.S. Food and Drug Administration approved high-dose bolus IL-2 as a single agent in 1992 after the demonstration of durable responses in mRCC patients (28). In 1998, IL-2 was also approved for the treatment of metastatic melanoma (MM) by demonstrating durable responses of $16 \%$ ORR with $6 \%$ CRs, $10 \%$ PRs, and 5.9 months median response duration among 270 patients with MM (29). Continuous infusions of low-dose IL-2 were also evaluated for up to 3 months. This regimen showed positive responses by showing selective differentiation and expansion of NK cells without severe toxicities, although cell activation was not observed (30-33). IL-2 administration has also been widely tested in adoptive T-cell therapy with autologous tumorinfiltrating lymphocytes and chimeric antigen receptor T cells (34)

Despite its considerable antitumor efficacy during several clinical trials, IL-2 therapy has still been done carefully because of the severe toxicities induced by the high-dose administration needed to achieve an immune-regulatory effect in tissues. Furthermore, the general limitation of immunotherapy with recombinant proteins is the short half-life and their low, unstable bioactivity. The direct binding of IL-2 to IL-2R $\alpha$-expressing endothelial cells is considered to induce vascular leak syndrome (VLS), which is associated with the severe vascular failures of high-dose IL-2 immunotherapy (35). Moreover, the expansion of immunosuppressive $T_{\text {REG }}$ cells might also interfere with the efficacy of highdose IL-2 immunotherapy (36).

To avoid the strong binding of IL-2 to high-affinity IL-2Rs, one group of researchers generated IL-2 mutants called IL-2 'superkines' (also called super-IL-2) by increasing their binding affinities for IL-2R $\beta(37,38)$. The IL-2 superkines showed improved antitumor responses in vivo with a superior expansion of $\mathrm{CD}^{+} \mathrm{T}$ cells and NK cell-mediated cytotoxicity, but also increased $\mathrm{T}_{\text {REG }}$ cells at a lesser proportion. An alternative approach to inhibiting the systemic expansion of $T_{\text {REG }}$ cells is to generate IL-2 agents that directly target tumor-associated antigens (TAAs). IL-2 targeting several types of TAAs, such as epithelial cell adhesion molecules (EpCAM), carcinoembryonic antigens (CEA), and $\mathrm{CD} 20$, has been presented in a wide range of clinical trials (39). Currently, targeting the tumor extracellular matrix (ECM) proteins is also considered a good targeting strategy. Since collagen within tumor tissues is more accessible to collagen-binding proteins in blood than in other tissues because of the leaky vasculature, one group of researchers focused on the targeting of a specific collagen-binding domain (CBD) (40). The IL-2 conjugated with the specific CBD (CBD-IL-2) led to increased antitumor efficacy coupled with increased tumor-infiltrating $\mathrm{CD}^{+}$ $T$ cells without systemic toxicity.

In addition to the regulation of IL-2 binding specificity, other approaches were tried to improve the serum half-life and bioactivity of IL-2. One method is to use cytokine complexes that 
are formed by combining a cytokine with an anti-cytokine antibody or a respective soluble cytokine receptor. Although why the cytokine complexes show increased bioactivity in vivo is unclear, IL-2 cytokine complexes with neutralizing antibodies have been most widely used among various cytokines (41). Cell subset targeting by IL-2 complexes is dependent on the clones of neutralizing antibodies. For example, treatment of the IL-2 complex with clone S4B6 antibody increases CD8 ${ }^{+} \mathrm{T}$ cells and NK cells, whereas a complex with clone JES6-1 antibody predominantly expands $T_{\text {REG }}$ cells $(9,35,42)$. Therefore, the conformational difference in the binding site for each antibody is considered to target a particular cell subset depending on its IL-2R affinity. Treatment with IL-2/S4B6 complex inhibits metastasis of melanoma, and the effects seem to depend on the increased NK cell activity but not on $\mathrm{CD}^{+}{ }^{+} \mathrm{T}$ cells, whereas they are also increased significantly after the treatment $(35,42$, 43). Another method is the conjugation of recombinant cytokines with a fragment-crystallizable $(\mathrm{Fc})$ region of the $\lg \mathrm{G}$ antibody. Since neonatal Fc receptor ( $F c R n)$ inhibits degradation of the Fc-fused antibodies and increases their half-lives by capturing the Fc and inducing recycling (44). Recently, treatment with Fc-fused IL-2 increased antitumor responses with the administration of an anti-tumor-antigen antibody (45). The combination therapy induced tumor infiltration of $\mathrm{CD}^{+}{ }^{+} \mathrm{T}$ cells, NK cells, neutrophils, and macrophages. Although $\mathrm{T}_{\mathrm{REG}}$ cells also slightly increased in tumors, that seemed not to affect the therapeutic efficacy. The researchers suggested that the innate immune responses increased by the combination therapy might support
T-cell-mediated effector functions and consequentially overcome the immune suppression of the $T_{\text {REG }}$ cells.

Another group of researchers developed a super mutant IL-2-FC (also called sumlL-2Fc) by conjugating Fc fragments and introducing mutations to make a stable IL-2 with increased IL-2R $\beta$ binding. SumlL-2Fc showed increased antitumor activity to native IL-2 therapy showing a selective increase of $\mathrm{CD} 8^{+} \mathrm{T}$ cells but not of $T_{\text {REG }}$ cells (46). Polyethylene glycol (PEG) conjugated IL-2 (PEG-IL-2) was also administered to mRCC and MM patients to increase IL-2 persistence; however, it did not increase antitumor activity more than did high-dose IL-2 (47). In 2016, Nektar Therapeutics, a biopharmaceutical company in CA, developed another form of PEGylated IL-2 by conjugating six releasable PEG linkers (also known as NKTR-214 or Bempegaldesleukin) (48). The NKTR-214 was designed as a prodrug showing increased persistence with an inhibited IL-2R $\alpha$ binding because of the location of the PEG chain at the binding interface. Treatment with NTKR-214 induced superior antitumor responses by inducing an increase of $\mathrm{CD}^{+} \mathrm{T}$ cells and their functionality as a single agent or as combination therapies with vaccination and with checkpoint inhibitors $(48,49)$. The recent approaches using IL-2 in cancer therapy are summarized in Fig. 1.

\section{BIOLOGY OF IL-7}

IL-7 is a 25-kDa glycoprotein that was first discovered in the 1980 s and plays pleiotropic roles in the homeostasis of lymphocytes, especially T cells. In general, non-hematopoietic stromal

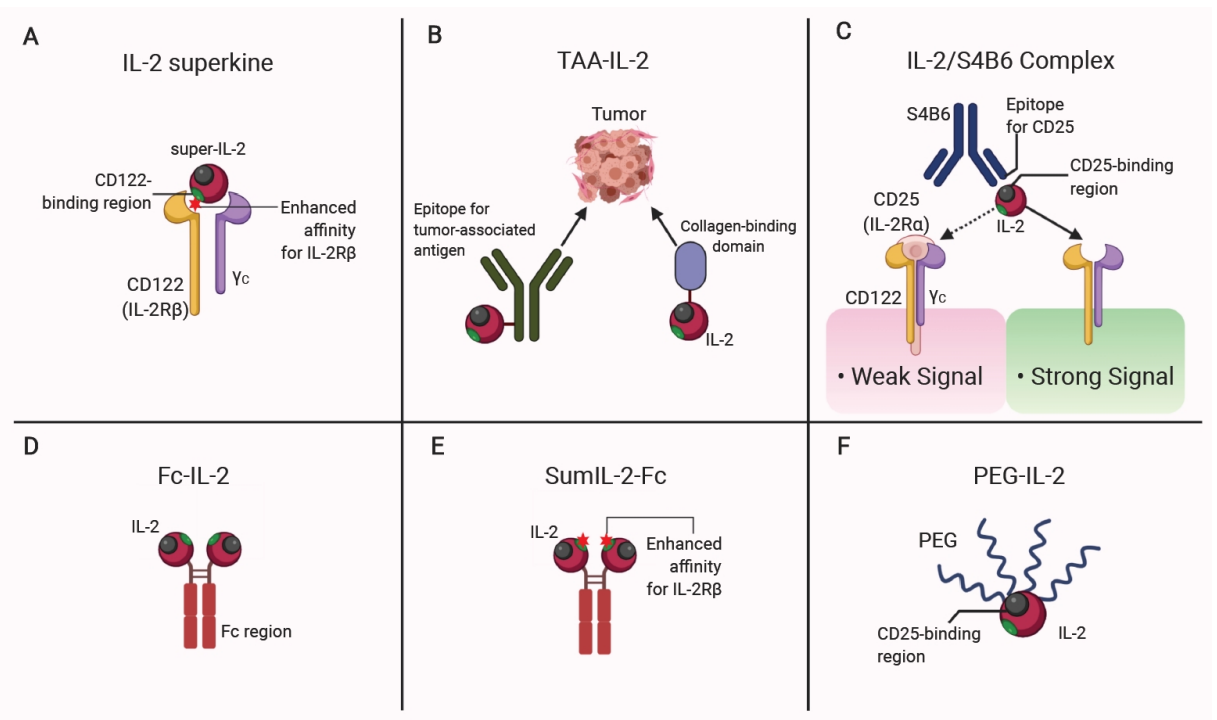

Fig. 1. Modification of IL-2 for anticancer therapy. (A) Mutations in CD122 (IL-2Rß)-binding regions of IL-2 superkines (Super-IL-2) increase binding affinity of IL-2 for IL-2R $\beta$ than CD25 (IL-2R $\alpha$ ). (B) The conjugation with antibody to tumor-associated antigens (TAAs) or collagen-binding domain delivers IL-2 to tumor sites. (C) The IL-2 complex with a neutralizing antibody clone S4B6 predominantly targets cells expressing dimeric IL-2R $\beta \gamma$. (D) Fc-fused IL-2 has a prolonged serum half-life. (E) Fc-fused mutant IL-2 shows an increased half-life with enhanced binding affinity for IL-2RR. (F) The conjugation of polyethylene glycol (PEG) shows increased IL-2 persistence with an inhibited IL-2R $\alpha$ binding. Figure created with BioRender.com. 
cells in diverse tissues are known as the main producers of IL-7 (50). Most recently, a subset of fibroblastic reticular cells (FRCs) in T-cell zones of lymph nodes was identified as an important cellular source of IL-7 for the homeostasis of peripheral T cells (51). However, the identification of exact sources, whether they are tissues or cell types, needs to be further elucidated, since the expression profiles examined so far remain controversial depending on the study models (52). Moreover, a subset of DCs is also known to produce small amounts of IL-7, whereas the lymphocytes, including T cells, B cells, and NK cells, do not (53).

IL-7R is a heterodimer consisting of 2 subunits, IL-7R $\alpha$ (CD127) complexed with the $\gamma \mathrm{c}$. Whereas IL-2R $\alpha$ constructs a high-affinity receptor specific for IL-2, IL-7R $\alpha$ is not specific for IL-7 but is also shared with thymic stromal lymphopoietin (TSLP), which is also important for the thymic development of T cells (54). Therefore, IL-7R $\alpha$-deficient mice seem to develop the severe tendency of lymphopenia more than IL-7-deficient mice, and mice without both molecules show the phenotype of severe combined immunodeficiency (SCID) $(55,56)$. IL-7R $\alpha$ is broadly expressed throughout the lymphoid system. IL-7 is a critical factor for the development and maintenance of the diverse range of lymphoid cells, since common-lymphoid progenitor in the bone marrow (BM) also expresses the IL-7R $\alpha$ and develops into the diverse lymphoid populations. Although mature B cells in the periphery lose the expression of IL-7R $\alpha$, IL-7 is still an important factor for B-cell development by regulating the proliferation and survival of B-cell progenitors in the BM (57). Despite its essential role in mouse B cells, the requirement of IL-7 in human B-cell development is controversial, since some patients with SCID expressing the mutant IL-7R showed a normal number of B cells (58). Nevertheless, IL-7 has also been implicated as a homeostatic mediator of B-cell progenitors. The importance of IL-7 signaling on T-cell homeostasis is well defined. In the thymus, thymopoiesis proceeds through, in order, the double-negative ( $\mathrm{DN}$; $\left.\mathrm{CD}^{-}{ }^{-} \mathrm{CD} 8^{-}\right)$, double-positive (DP; $\mathrm{CD} 4^{+} \mathrm{CD}^{+}$), and single-positive (SP) $\mathrm{CD} 4^{+}$or $\mathrm{CD} 8^{+}$progenitor cells. IL-7R $\alpha$ is highly expressed in the early stage of DN cells and then downregulated on DP cells followed by re-expression on SP cells. Severe loss of DN cells and immunodeficiency in the absence of IL-7 signaling showed a pivotal requirement of IL-7 for T-cell development (59). Although IL-7 plays a major role in the development of both $\alpha \beta$ and $\gamma \delta$ T cells, $\alpha \beta$ T cells but not $\gamma \delta$ T cells can be partially restored through the transgenic expression of anti-apoptotic molecules, such as B-cell lymphoma $2(\mathrm{BCl} 2)$, suggesting that IL-7 signaling is essential for the survival of thymocytes (60-64). Furthermore, IL-7 signaling also regulates $\beta$-selection and TCR rearrangement during the DN stage (65). Development of $\gamma \delta$ T cells seems to depend more on the source of IL-7, since IL-7 deficiency specific for the thymic epithelial cells, but not for intestinal intraepithelial cells, showed a decrease in $\gamma \delta$ T cells $(66,67)$. Unlike mature $B$ cells, IL-7R $\alpha$ is highly expressed on the recent thymic emigrants (RTEs), naïve T cells, and memory T cells in the periphery.
IL-7R $\alpha$ is also expressed on mouse thymic NK cells (CD11b CD $16^{-} \mathrm{CD} 9^{\text {hi }}$ Ly $9^{\text {lo }}$ ), which are similar to human CD $56^{\text {hi }}$ CD 16 NK cells, showing reduced cytotoxicity but increased production of inflammatory cytokines (68). For DCs, IL-7R $\alpha$ is expressed only on migratory DCs in vivo, whereas it is constitutively expressed on BM-derived DCs in vitro (69). Although the expression of IL-7R $\alpha$ is restricted to a subset of mature DCs, the development of whole DC subsets is likely to be influenced by IL-7 signaling through the IL-7R $\alpha$-expressing progenitor cells in the BM. Furthermore, IL-7-mediated signaling in DCs regulates MHC-II-restricted homeostatic proliferation of $\mathrm{CD}^{+}{ }^{+} \mathrm{T}$ cells (53).

\section{EFFECT ON T-CELL HOMEOSTASIS; IL-2 VS. IL-7}

Following thymic export, RTEs induce prolonged survival and proliferate through IL-7 signaling without TCR stimulation (70, 71). However, the survival and differentiation of non-RTE mature $\mathrm{T}$ cells depend on signals through TCR as well as cytokines $(72,73)$. IL-7 would regulate naïve $T$ cells directly more than IL-2 does since the expression level of IL-7R $\alpha$ is higher than that of IL-2R $\alpha$, which is relatively low in naïve T cells. Although IL-7 signaling is required for both survival and proliferation of naïve T cells, the homeostatic proliferation is more remarkable under lymphopenic conditions (74-76). IL-7 is known to regulate the quantity of CD8 co-receptor expressed in a feedback loop to control TCR engagement to self-antigens. Since the only ligands available for T cells are the self-antigens during homeostatic proliferation, IL-7 seems to regulate the proliferation by increasing the weak TCR signaling (77). After TCR stimulation, the recently activated T cells not only increase the expression of IL-2R $\alpha$ but also become a major source of IL-2 themselves (22). With regard to the polarization of $\mathrm{CD}^{+} \mathrm{T}_{\mathrm{H}}$ subset differentiation, low expression of IL-7R $\alpha$ defines immunosuppressive $T_{\text {REG }}$ cells by inversely correlating with the Foxp3 expression, whereas the IL-2 signaling induces the Foxp3 $(12,78,79)$. As previously mentioned, the cell-fate decision of $\mathrm{CD}^{+} \mathrm{T}$ cells is regulated in a contrary direction between IL-2 and IL-7 signaling (Fig. 2). Whereas the strong IL-2 signaling mediates the differentiation toward terminal effector cells, a subset of activated $\mathrm{CD}^{+} \mathrm{T}$ cells expressing a high level of IL-7R $\alpha$ display a phenotype of memory T cells (22). In addition to the expression of anti-apoptotic molecules, IL-7 signaling also mediates the long-term survival of T cells by increasing glucose uptake $(80,81)$. More recently, it has also been reported that IL-7 specifically controls the longevity of $\mathrm{CD}^{+}$memory $\mathrm{T}$ cells by inducing triglyceride synthesis followed by sustained ATP levels (82). Although IL-7 is closer to a 'home-

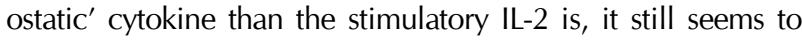
affect the effector functions of T cells. Continuous IL-7 signaling not only generates cells expressing memory markers but also induces production of IFN $\gamma$ followed by IFN $\gamma$-induced cell death during homeostasis (83). Therefore, elucidation of T-cell responses after IL-7-mediated immunotherapy might be therapeutically more significant. 


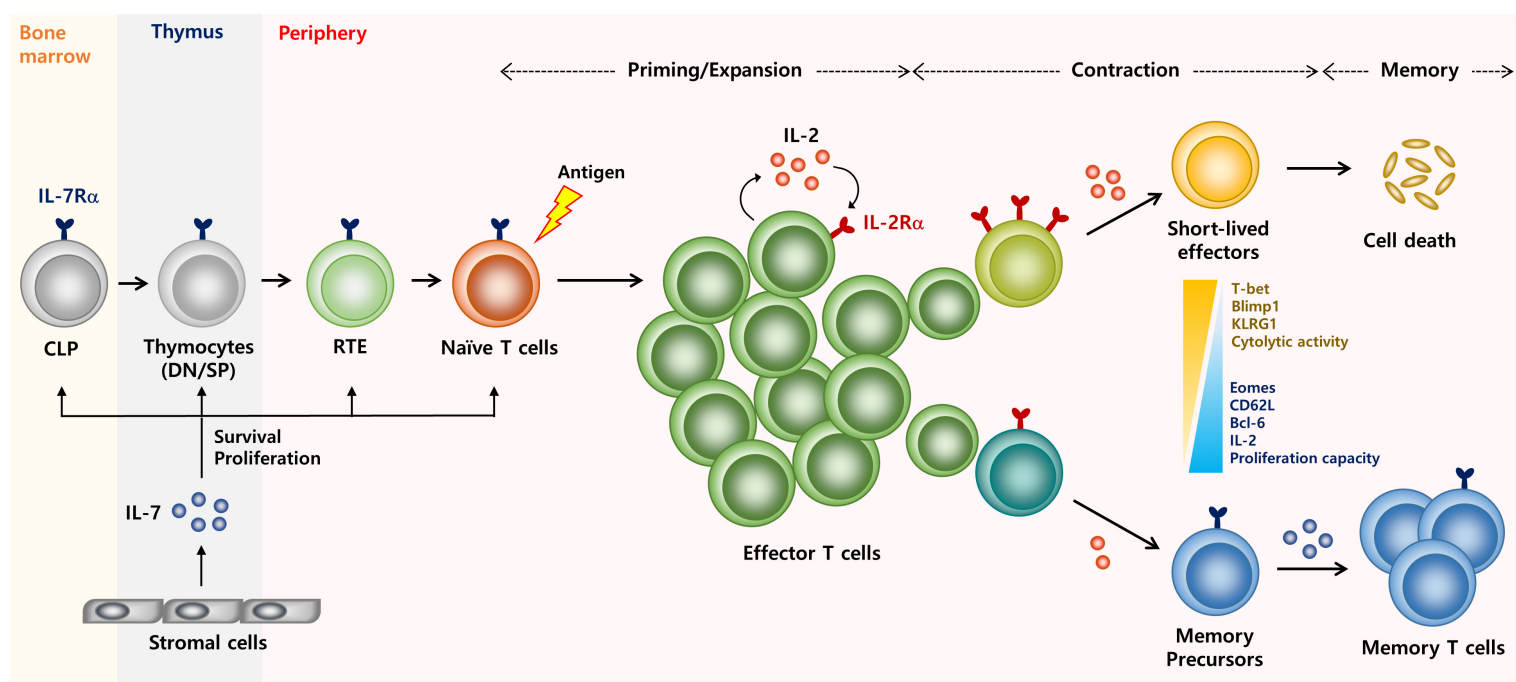

Fig. 2. Overview of CD8 T cell immunity regulated by IL-2 and IL-7. The receptor for IL-7 is expressed on the naïve and memory T cells including precursors cells; common lymphoid progenitors (CLP), double-positive, and single-positive thymocytes, and recent thymic emigrants (RTE). IL-7 is mainly produced by stromal cells and gives a signal to IL-7R $\alpha$-expressing cells to regulate their survival, proliferation, and maintenance. By contrast, the IL-2 receptors are highly induced on activated T cells after antigenic stimulation and the cells themselves also become a major producer of IL-2. After rapid expansion, the effector T cells develop into different fates depending on the amount of IL-2 signaling. Cells expressing high levels of IL-2R $\alpha$ receive strong IL-2 signaling and become short-lived effector cells showing increased expression of Blimp1, KLRG1, and cytolytic activity. Cells expressing low levels of IL-2R $\alpha$ receive relatively weak IL-2 signaling and become memory precursor cells showing increased expression of IL-7R $\alpha, \mathrm{CD} 62 \mathrm{~L}$, IL-2 production, and proliferation capacity but decreased expressions of effector-associated molecules above. The re-expression of IL-7R $\alpha$ on memory $\mathrm{T}$ cells capable of maintaining the long-term survival of the cells.

\section{CANCER THERAPY WITH IL7}

Unlike IL-2, clinical trials with IL-7 as cancer immunotherapy have reported no objective responses, whereas preclinical studies have shown the potential antitumor activity of IL-7 therapy. However, dramatic changes in pharmacodynamics associated with beneficial immunological phenotypes have been widely announced through clinical trials. The Cytheris Corp., now RevImmune, Inc., has mainly developed immunotherapy with recombinant human IL-7 (rhlL-7). The first clinical trial was carried out with the rhIL-7 produced in E.coli (also known as CYT 99-007) for 11 patients with MM and 1 patient with metastatic sarcoma. The highest dose, $60 \mu \mathrm{g} / \mathrm{kg}$, elicited a serum half-life of about 12 hours. A dose-dependent increase of both $\mathrm{CD}^{+}$and $\mathrm{CD} 8^{+}$ $T$ cells and a reduced frequency of $\mathrm{T}_{\text {REG }}$ cells were observed during therapy. In some patients, $\mathrm{CD} 19^{+} \mathrm{CD} 10^{+}$B-cell progenitors were also increased in the BM without any sign of hematopoietic neoplasm (84). Since the non-glycosylated first-generation rhIL-7 elicited a minor titer of anti-drug antibodies, subsequent clinical trials were carried out with a glycosylated rhIL-7 produced by eukaryotic cells (also known as CYT107). Sixteen patients with non-hematologic refractory cancers were treated, and a dose-dependent increase of $T$ cells without enrichment of $T_{\text {REG }}$ cells was also observed with regard to the increased expression of a proliferation marker, Ki67, and the $\mathrm{BCl} 2$ (85). TCR diversity was also increased after IL-7 therapy. In patients with lymphopenic metastatic breast cancers, rhlL-7 administration before chemotherapy significantly increased $\mathrm{CD}^{+}$and $\mathrm{CD}^{+}$ T-cell counts, but could not increase cells expressing inflammatory cytokines (86). Adjuvant immunotherapy of rhlL-7 with various tumor vaccines has also proceeded in several clinical trials $(87,88)$. A clear difference in immunotherapy between IL-2 and IL-7 is the toxicity issue. Unlike IL-2, clinical studies of both non-glycosylated and glycosylated rhIL-7 showed a welltolerated dose range with mild symptoms, such as transient injection-site reactions and reversible enlargement of lymphoid organs $(84-87,89)$.

The antitumor potency of IL-7 therapy has been demonstrated in preclinical studies. Intratumoral delivery of IL-7-transduced DCs induced superior antitumor responses with increased production of granulocyte-macrophage colony-stimulating factor (GM-CSF) and IFNy (90). Treatment of IL-7 with GM-CSF-secreting tumor vaccines also improved the survival of tumor-bearing mice by increasing activated DCs and T cells within draining lymph nodes with the increased cytolytic T cells within tumors (91). These results further demonstrated the importance of both innate and adaptive immunity against cancer immunotherapy with IL-7. Adjuvant treatment of IL-7 with a vaccination regimen improved the survival of tumor-bearing mice by augmenting the vaccine-induced tumor-specific $\mathrm{CD}^{+}{ }^{+} \mathrm{T}$-cell responses. In this setting, adjuvant treatment with IL-7 not only increased the pathogenic properties of the $\mathrm{CD}^{+} \mathrm{T}$ cells but also made them 
refractory to the TGF $\beta$-mediated inhibitory network (92).

In addition to the use of native IL-7 cytokine, efforts to increase the bioactivity of IL-7 have also been developed. One group of researchers showed that the treatment of an IL-7 complex formed with an IL-7R $\alpha$-Fc induced antitumor responses by increasing tumor infiltration of T cells through CXCR3 chemokine signaling (93). An IL-7 complex with a neutralizing antibody clone M25 is also known to have increased bioactivity. Treatment of the IL-7 complexes induced a massive increase of naïve and memory $\mathrm{T}$ cells in normal mice and also restored the impaired thymopoiesis in IL-7-deficient mice. Unlike the IL-2 neutralizing antibody S4B6, treatment with M25 did not induce cell proliferation either by itself or by separately injecting it even one minute after IL-7. Furthermore, IL-7 complexes with an M25 antigen-binding fragment (Fab) also did not show mitogenic activity. These results suggest that both the pre-mixture form of the complexes ex vivo and the Fc region of the neutralizing antibody must be required for higher bioactivity in vivo (94). Indeed, the IL-7 complexes induced the majority of increased bioactivity through the interaction between FcRn and Fc. Treatment of Fc-fused IL-7 (IL-7-FC) also showed FCRndependent mitogenic activity that is slightly lower than that of IL-7 complexes (95). The FC region of the previous IL-7-FC is a mutated protein displaying no antibody-dependent cell-mediated cytotoxicity (ADCC) and complement-dependent cytotoxicity (CDC) through the inhibited binding to Fc $\gamma R$ and $\mathrm{C} 1 \mathrm{q}$ (96). Immunotherapy with a human isoform of the IL-7-FC has also proceeded in clinical trials. Genexine, Inc., developed a hybridFc fused rhlL-7 (also known as rhlL-7-hyFc, or Efineptakin alfa) that has an extended half-life and reduced off-target immunogenicity. Systemic administration of rhIL-7-hyFc has currently been demonstrated as a well-tolerated agent increasing $T$ cells in healthy volunteers (97). In preclinical models, adjuvant treatment of rhIL-7-hyFc with a DNA vaccine showed CD8 ${ }^{+}$T-celldependent antitumor responses (98). We have also recently reported that the antitumor response of rhIL-7-hyFc is mediated not only by increasing diverse aspects of $\mathrm{CD}^{+} \mathrm{T}$-cell responses but also by decreasing immunosuppressive subsets within tumors, consequently by inducing an inflamed TME (99). Multiple clinical trials are now proceeding to verify the antitumor benefits of rhlL-7-hyFc, led by NeolmmuneTech. The approaches using IL-7 in cancer therapy are summarized in Fig. 3.

\section{CONCLUSION}

The current understanding of cancer immunotherapy indicates that most anticancer therapies regulate the immune response of the cancer patients, especially toward increasing the tumor-specific T-cell responses, whether the therapeutic agent directly targets T cells or not. In general, prolonged survival of patients correlates with the number of cytotoxic/memory $T$ cells, $T_{H} 1$ cells, and other effector cells. In contrast, an increased number of immunosuppressive cells, including $T_{\text {REG }}$ cells and myeloidderived suppressor cells, are associated with poor prognosis. It has also been discovered that the densities, phenotypes, and characteristics of individual immune cells in TME may affect the efficacy of immunotherapy. Given that the immune response in TME has chaotic complexity, it is not surprising that the

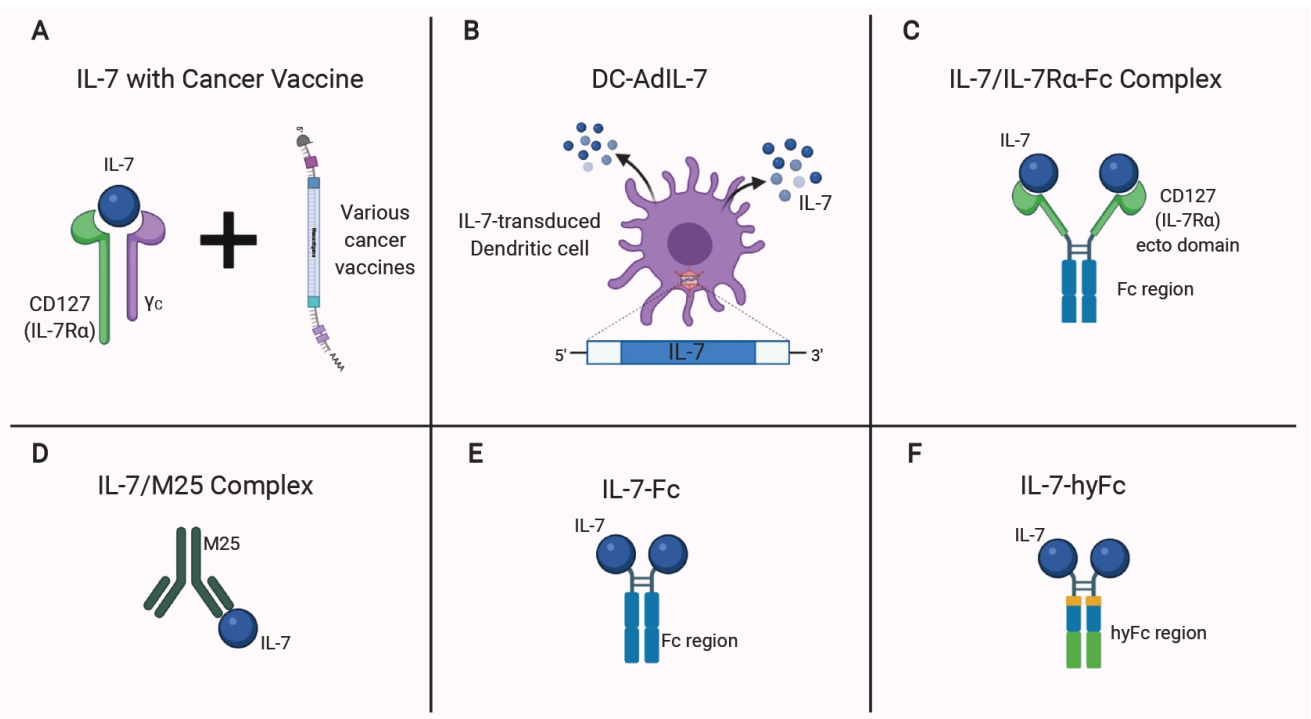

Fig. 3. Modification of IL-7 for anticancer therapy. (A) Adjuvant treatment of IL-7 and its receptor complex enhances the potency of cancer vaccines. (B) Intratumoral administration of IL-7-transduced DCs (DC-AdIL-7) induces direct IL-7 signals in the tumor site. (C-F) Engineered IL-7 complexes with enhanced bioactivity. (C) IL-7 complexed with IL-7R $\alpha-F C$. (D) IL-7 complex with a monoclonal antibody clone M25. (E) IL-7 fused with the Fc region of the antibody. (F) IL-7 fused to a hybrid FC (IgD/lgG4) has a prolonged serum half-life without cytotoxicity on target cells. Figure created with BioRender.com. 
currently emerging prime immunotherapies with checkpoint inhibitors (CPIs) cannot conquer cancers yet, but they are taking priority in most clinical trials nowadays. Epidemiological studies have demonstrated that it is crucial to choose the right pair for combined immunotherapy rather than focusing on the single therapeutic agent that regulates only a fraction of immune response in TME. Since IL-2 and IL-7 have been well defined to increase the T-cell responses, they could be the best partners for most immunotherapies, including the CPIs. Although the augmented T-cell responses by the cytokine therapy have been observed, it remains to be seen how these cytokines may change the heterogeneous phenotypes of $\mathrm{T}$ cells and their functional characteristics in TME. Indeed, since the single-cell analysis technique is necessary for revealing the conditional change of TME, it is becoming important not only to understand the detailed mechanism but also to interpret it for the development of successful therapeutic strategies. Overall, we believe that therapeutic challenges with the T-cell regulators, IL-2 and IL-7, will be the promising strategies for anticancer immunotherapy if the detailed mechanisms of T-cell responses in TME are followed.

\section{ACKNOWLEDGEMENTS}

This work has supported by the Research Institute of Neolmmune Tech, Inc., and by the Bio \& Medical Technology Development Program of the National Research Foundation (NRF) funded by the Korean government (MSIT) (2017M3A9C8033570).

\section{CONFLICTS OF INTEREST}

The authors have no conflicting interests.

\section{REFERENCES}

1. Chen DS and Mellman I (2013) Oncology meets immunology: the cancer-immunity cycle. Immunity 39, 1-10

2. Fridman WH, Pages F, Sautes-Fridman C and Galon J (2012) The immune contexture in human tumours: impact on clinical outcome. Nat Rev Cancer 12, 298-306

3. Menetrier-Caux C, Ray-Coquard I, Blay JY and Caux C (2019) Lymphopenia in cancer patients and its effects on response to immunotherapy: an opportunity for combination with cytokines? J Immunother Cancer 7, 85

4. Leonard WJ, Lin JX and O'Shea JJ (2019) The gammac family of cytokines: basic biology to therapeutic ramifications. Immunity 50, 832-850

5. Morgan DA, Ruscetti FW and Gallo R (1976) Selective in vitro growth of $\mathrm{T}$ lymphocytes from normal human bone marrows. Science 193, 1007-1008

6. Boyman O and Sprent J (2012) The role of interleukin-2 during homeostasis and activation of the immune system. Nat Rev Immunol 12, 180-190

7. Wang X, Rickert M and Garcia KC (2005) Structure of the quaternary complex of interleukin-2 with its alpha, beta, and gammac receptors. Science 310, 1159-1163

8. Zhang X, Sun S, Hwang I, Tough DF and Sprent J (1998)
Potent and selective stimulation of memory-phenotype CD8 + T cells in vivo by IL-15. Immunity 8, 591-599

9. Boyman O, Kovar M, Rubinstein MP, Surh CD and Sprent J (2006) Selective stimulation of T cell subsets with antibodycytokine immune complexes. Science 311, 1924-1927

10. Sakaguchi S (2004) Naturally arising CD4 + regulatory T cells for immunologic self-tolerance and negative control of immune responses. Annu Rev Immunol 22, 531-562

11. Liao W, Lin JX, Wang L, Li P and Leonard WJ (2011) Modulation of cytokine receptors by IL-2 broadly regulates differentiation into helper T cell lineages. Nat Immunol 12, 551559

12. Yang XP, Ghoreschi K, Steward-Tharp SM et al (2011) Opposing regulation of the locus encoding IL-17 through direct, reciprocal actions of STAT3 and STAT5. Nat Immunol $12,247-254$

13. Liao W, Spolski R, Li P et al (2014) Opposing actions of IL-2 and IL-21 on Th9 differentiation correlate with their differential regulation of BCL6 expression. Proc Natl Acad Sci U S A 111, 3508-3513

14. Laurence A, Tato CM, Davidson TS et al (2007) Interleukin-2 signaling via STAT5 constrains T helper 17 cell generation. Immunity 26, 371-381

15. Ballesteros-Tato A, Leon B, Graf BA et al (2012) Interleukin-2 inhibits germinal center formation by limiting $T$ follicular helper cell differentiation. Immunity 36, 847-856

16. Sadlack B, Lohler J, Schorle H et al (1995) Generalized autoimmune disease in interleukin-2-deficient mice is triggered by an uncontrolled activation and proliferation of CD4 + T cells. Eur J Immunol 25, 3053-3059

17. Willerford DM, Chen J, Ferry JA, Davidson L, Ma A and Alt FW (1995) Interleukin-2 receptor alpha chain regulates the size and content of the peripheral lymphoid compartment. Immunity 3, 521-530

18. Suzuki H, Kundig TM, Furlonger $C$ et al (1995) Deregulated $T$ cell activation and autoimmunity in mice lacking interleukin-2 receptor beta. Science 268, 1472-1476

19. Almeida AR, Legrand N, Papiernik M and Freitas AA (2002) Homeostasis of peripheral CD4 + T cells: IL-2R alpha and IL-2 shape a population of regulatory cells that controls CD4 + T cell numbers. J Immunol 169, 4850-4860

20. Malek TR, Yu A, Vincek V, Scibelli P and Kong L (2002) CD4 regulatory $T$ cells prevent lethal autoimmunity in IL-2 Rbeta-deficient mice. Implications for the nonredundant function of IL-2. Immunity 17, 167-178

21. Fontenot JD, Rasmussen JP, Gavin MA and Rudensky AY (2005) A function for interleukin 2 in Foxp3-expressing regulatory T cells. Nat Immunol 6, 1142-1151

22. Kalia V, Sarkar S, Subramaniam S, Haining WN, Smith KA and Ahmed R (2010) Prolonged interleukin-2Ralpha expression on virus-specific CD8 + T cells favors terminal-effector differentiation in vivo. Immunity 32, 91-103

23. Pipkin ME, Sacks JA, Cruz-Guilloty F, Lichtenheld MG, Bevan MJ and Rao A (2010) Interleukin-2 and inflammation induce distinct transcriptional programs that promote the differentiation of effector cytolytic T cells. Immunity 32, 79-90

24. Lenardo M, Chan KM, Hornung F et al (1999) Mature T lymphocyte apoptosis-immune regulation in a dynamic and unpredictable antigenic environment. Annu Rev Immunol 


\section{$17,221-253$}

25. Rosenberg SA, Lotze MT, Muul LM et al (1985) Observations on the systemic administration of autologous lymphokine-activated killer cells and recombinant interleukin-2 to patients with metastatic cancer. N Engl J Med 313, 1485-1492

26. Rosenberg SA, Lotze MT, Aebersold PM, Linehan WM, Seipp CA and White DE (1989) Experience with the use of high-dose interleukin-2 in the treatment of 652 cancer patients. Ann Surg 210, 474-485

27. Rosenberg SA, Yang JC, Topalian SL et al (1994) Treatment of 283 consecutive patients with metastatic melanoma or renal cell cancer using high-dose bolus interleukin 2. JAMA 271, 907-913

28. Fyfe G, Fisher RI, Rosenberg SA, Sznol M, Parkinson DR and Louie AC (1995) Results of treatment of 255 patients with metastatic renal cell carcinoma who received high-dose recombinant interleukin-2 therapy. J Clin Oncol 13, 688-696

29. Atkins MB, Lotze MT, Dutcher JP et al (1999) High-dose recombinant interleukin 2 therapy for patients with metastatic melanoma: analysis of 270 patients treated between 1985 and 1993. J Clin Oncol 17, 2105-2116

30. Caligiuri MA, Murray C, Robertson MJ et al (1993) Selective modulation of human natural killer cells in vivo after prolonged infusion of low dose recombinant interleukin 2. J Clin Invest 91, 123-132

31. Caligiuri MA, Murray C, Soiffer RJ et al (1991) Extended continuous infusion low-dose recombinant interleukin-2 in advanced cancer: prolonged immunomodulation without significant toxicity. J Clin Oncol 9, 2110-2119

32. Soiffer RJ, Murray C, Shapiro C et al (1996) Expansion and manipulation of natural killer cells in patients with metastatic cancer by low-dose continuous infusion and intermittent bolus administration of interleukin 2. Clin Cancer Res 2, 493-499

33. Fehniger TA, Bluman EM, Porter MM et al (2000) Potential mechanisms of human natural killer cell expansion in vivo during low-dose IL-2 therapy. J Clin Invest 106, 117-124

34. Wrangle JM, Patterson A, Johnson CB et al (2018) IL-2 and beyond in cancer immunotherapy. J Interferon Cytokine Res 38, 45-68

35. Krieg C, Letourneau S, Pantaleo G and Boyman O (2010) Improved IL-2 immunotherapy by selective stimulation of IL-2 receptors on lymphocytes and endothelial cells. Proc Natl Acad Sci U S A 107, 11906-11911

36. Sim GC, Martin-Orozco N, Jin L et al (2014) IL-2 therapy promotes suppressive ICOS + Treg expansion in melanoma patients. J Clin Invest 124, 99-110

37. Levin AM, Bates DL, Ring AM et al (2012) Exploiting a natural conformational switch to engineer an interleukin-2 'superkine'. Nature 484, 529-533

38. Ardolino M, Azimi CS, lannello A et al (2014) Cytokine therapy reverses NK cell anergy in MHC-deficient tumors. J Clin Invest 124, 4781-4794

39. Mortara L, Balza E, Bruno A, Poggi A, Orecchia P and Carnemolla B (2018) Anti-cancer therapies employing IL-2 cytokine tumor targeting: contribution of innate, adaptive and immunosuppressive cells in the anti-tumor efficacy. Front Immunol 9, 2905

40. Ishihara J, Ishihara A, Sasaki K et al (2019) Targeted anti- body and cytokine cancer immunotherapies through collagen affinity. Sci Transl Med 11, eaau3259

41. Mostbock S (2009) Cytokine/Antibody complexes: an emerging class of immunostimulants. Curr Pharm Des 15, 809-825

42. Kamimura D, Sawa $Y$, Sato $M$, Agung E, Hirano $T$ and Murakami M (2006) IL-2 in vivo activities and antitumor efficacy enhanced by an anti-IL-2 mAb. J Immunol 177, 306-314

43. Jin $\mathrm{GH}$, Hirano $\mathrm{T}$ and Murakami M (2008) Combination treatment with IL-2 and anti-IL-2 mAbs reduces tumor metastasis via NK cell activation. Int Immunol 20, 783-789

44. Roopenian DC and Akilesh S (2007) FcRn: the neonatal Fc receptor comes of age. Nat Rev Immunol 7, 715-725

45. Zhu EF, Gai SA, Opel CF et al (2015) Synergistic innate and adaptive immune response to combination immunotherapy with anti-tumor antigen antibodies and extended serum half-life IL-2. Cancer Cell 27, 489-501

46. Sun Z, Ren Z, Yang K et al (2019) A next-generation tumor-targeting IL-2 preferentially promotes tumor-infiltrating CD8(+) T-cell response and effective tumor control. Nat Commun 10, 3874

47. Yang JC, Topalian SL, Schwartzentruber DJ et al (1995) The use of polyehylene glycol-modified interleukin-2 (PEGIL-2) in the treatment of patients with metastatic renal cell carcinoma and melanoma. Cancer 76, 687-694

48. Charych DH, Hoch U, Langowski JL et al (2016) NKTR214, an engineered cytokine with biased IL2 receptor binding, increased tumor exposure, and marked efficacy in mouse tumor Models. Clin Cancer Res 22, 680-690

49. Sharma M, Khong H, Fa'ak F et al (2020) Bempegaldesleukin selectively depletes intratumoral Tregs and potentiates T cell-mediated cancer therapy. Nat Commun 11, 661

50. Mackall CL, Fry TJ and Gress RE (2011) Harnessing the biology of IL-7 for therapeutic application. Nat Rev Immunol 11, 330-342

51. Link A, Vogt TK, Favre $S$ et al (2007) Fibroblastic reticular cells in lymph nodes regulate the homeostasis of naive $T$ cells. Nat Immunol 8, 1255-1265

52. Kim GY, Hong C and Park JH (2011) Seeing is believing: illuminating the source of in vivo interleukin-7. Immune Netw 11, 1-10

53. Guimond M, Veenstra RG, Grindler DJ et al (2009) Interleukin 7 signaling in dendritic cells regulates the homeostatic proliferation and niche size of $\mathrm{CD} 4{ }^{+} \mathrm{T}$ cells. Nat Immunol 10, 149-157

54. Al-Shami A, Spolski R, Kelly J et al (2004) A role for thymic stromal lymphopoietin in CD4(+) T cell development. J Exp Med 200, 159-168

55. Peschon JJ, Morrissey PJ, Grabstein KH et al (1994) Early lymphocyte expansion is severely impaired in interleukin 7 receptor-deficient mice. J Exp Med 180, 1955-1960

56. von Freeden-Jeffry $U$, Vieira $P$, Lucian LA, McNeil $T$, Burdach SE and Murray R (1995) Lymphopenia in interleukin (IL)-7 gene-deleted mice identifies IL-7 as a nonredundant cytokine. J Exp Med 181, 1519-1526

57. Clark MR, Mandal M, Ochiai K and Singh H (2014) Orchestrating B cell lymphopoiesis through interplay of IL-7 receptor and pre-B cell receptor signalling. Nat Rev Immunol 14, 69-80

58. Puel A, Ziegler SF, Buckley RH and Leonard WJ (1998) 
Defective IL7R expression in $\mathrm{T}(-) \mathrm{B}(+) \mathrm{NK}(+)$ severe combined immunodeficiency. Nat Genet 20, 394-397

59. Mazzucchelli R and Durum SK (2007) Interleukin-7 receptor expression: intelligent design. Nat Rev Immunol 7, 144-154

60. Kondo M, Akashi K, Domen J, Sugamura K and Weissman IL (1997) Bcl-2 rescues T lymphopoiesis, but not B or NK cell development, in common gamma chain-deficient mice. Immunity 7, 155-162

61. Akashi K, Kondo M, von Freeden-Jeffry U, Murray R and Weissman IL (1997) Bcl-2 rescues T lymphopoiesis in interleukin-7 receptor-deficient mice. Cell 89, 1033-1041

62. Maraskovsky E, O'Reilly LA, Teepe M, Corcoran LM, Peschon JJ and Strasser A (1997) Bcl-2 can rescue T lymphocyte development in interleukin-7 receptor-deficient mice but not in mutant rag-1(-/-) mice. Cell 89, 1011-1019

63. Pellegrini $M$, Bouillet $P$, Robati $M$, Belz GT, Davey GM and Strasser A (2004) Loss of Bim increases T cell production and function in interleukin 7 receptor-deficient mice. J Exp Med 200, 1189-1195

64. Khaled AR, Li WQ, Huang J et al (2002) Bax deficiency partially corrects interleukin-7 receptor alpha deficiency. Immunity $17,561-573$

65. Boudil A, Matei IR, Shih HY et al (2015) IL-7 coordinates proliferation, differentiation and Tcra recombination during thymocyte beta-selection. Nat Immunol 16, 397-405

66. Moore TA, von Freeden-Jeffry U, Murray R and Zlotnik A (1996) Inhibition of gamma delta T cell development and early thymocyte maturation in IL-7 -/- mice. J Immunol $157,2366-2373$

67. Shitara S, Hara T, Liang B et al (2013) IL-7 produced by thymic epithelial cells plays a major role in the development of thymocytes and TCRgammadelta + intraepithelial lymphocytes. J Immunol 190, 6173-6179

68. Vosshenrich CA, Garcia-Ojeda ME, Samson-Villeger SI et al (2006) A thymic pathway of mouse natural killer cell development characterized by expression of GATA-3 and CD127. Nat Immunol 7, 1217-1224

69. Vogt TK, Link A, Perrin J, Finke D and Luther SA (2009) Novel function for interleukin-7 in dendritic cell development. Blood 113, 3961-3968

70. Soares MV, Borthwick NJ, Maini MK, Janossy G, Salmon $M$ and Akbar AN (1998) IL-7-dependent extrathymic expansion of CD45RA + T cells enables preservation of a naive repertoire. J Immunol 161, 5909-5917

71. Swainson L, Kinet S, Mongellaz C, Sourisseau M, Henriques $\mathrm{T}$ and Taylor N (2007) IL-7-induced proliferation of recent thymic emigrants requires activation of the PI3K pathway. Blood 109, 1034-1042

72. Ernst B, Lee DS, Chang JM, Sprent J and Surh CD (1999) The peptide ligands mediating positive selection in the thymus control T cell survival and homeostatic proliferation in the periphery. Immunity 11, 173-181

73. Goldrath AW and Bevan MJ (1999) Low-affinity ligands for the TCR drive proliferation of mature CD8 + T cells in lymphopenic hosts. Immunity 11, 183-190

74. Surh CD and Sprent J (2008) Homeostasis of naive and memory T cells. Immunity 29, 848-862

75. Surh CD and Sprent J (2005) Regulation of mature T cell homeostasis. Semin Immunol 17, 183-191
76. Hennion-Tscheltzoff O, Leboeuf D, Gauthier SD et al (2013) TCR triggering modulates the responsiveness and homeostatic proliferation of $\mathrm{CD} 4+$ thymic emigrants to IL-7 therapy. Blood 121, 4684-4693

77. Park JH, Adoro S, Lucas PJ et al (2007) 'Coreceptor tuning': cytokine signals transcriptionally tailor CD8 coreceptor expression to the self-specificity of the TCR. Nat Immunol 8, 1049-1059

78. Seddiki N, Santner-Nanan B, Martinson J et al (2006) Expression of interleukin (IL)-2 and IL-7 receptors discriminates between human regulatory and activated $T$ cells. J Exp Med 203, 1693-1700

79. Liu W, Putnam AL, Xu-Yu Z et al (2006) CD127 expression inversely correlates with FoxP3 and suppressive function of human CD4 + T reg cells. J Exp Med 203, 1701-1711

80. Barata JT, Silva A, Brandao JG, Nadler LM, Cardoso AA and Boussiotis VA (2004) Activation of PI3K is indispensable for interleukin 7-mediated viability, proliferation, glucose use, and growth of $\mathrm{T}$ cell acute lymphoblastic leukemia cells. J Exp Med 200, 659-669

81. Wofford JA, Wieman HL, Jacobs SR, Zhao Y and Rathmell JC (2008) IL-7 promotes Glut1 trafficking and glucose uptake via STAT5-mediated activation of Akt to support T-cell survival. Blood 111, 2101-2111

82. Cui GL, Staron MM, Gray SM et al (2015) IL-7-induced glycerol transport and TAG synthesis promotes memory CD8(+) T cell longevity. Cell 161, 750-761

83. Kimura MY, Pobezinsky LA, Guinter TI et al (2013) IL-7 signaling must be intermittent, not continuous, during CD8 (+) T cell homeostasis to promote cell survival instead of cell death. Nat Immunol 14, 143-151

84. Rosenberg SA, Sportes C, Ahmadzadeh M et al (2006) IL-7 administration to humans leads to expansion of $\mathrm{CD} 8^{+}$and $\mathrm{CD}^{+}$cells but a relative decrease of $\mathrm{CD}^{+}{ }^{+}$T-regulatory cells. J Immunother 29, 313-319

85. Sportes C, Hakim FT, Memon SA et al (2008) Administration of rhlL-7 in humans increases in vivo TCR repertoire diversity by preferential expansion of naive $T$ cell subsets. J Exp Med 205, 1701-1714

86. Tredan O, Menetrier-Caux C, Ray-Coquard I et al (2015) ELYPSE-7: a randomized placebo-controlled phase Ila trial with CYT107 exploring the restoration of $\mathrm{CD}^{+}$lymphocyte count in lymphopenic metastatic breast cancer patients. Ann Oncol 26, 1353-1362

87. Merchant MS, Bernstein D, Amoako M et al (2016) Adjuvant immunotherapy to improve outcome in high-risk pediatric sarcomas. Clin Cancer Res 22, 3182-3191

88. Reimers MA, Slane KE and Pachynski RK (2019) Immunotherapy in metastatic castration-resistant prostate cancer: past and future strategies for optimization. Curr Urol Rep 20,64

89. Sportes C, Babb RR, Krumlauf MC et al (2010) Phase I study of recombinant human interleukin-7 administration in subjects with refractory malignancy. Clin Cancer Res 16, 727-735

90. Miller PW, Sharma S, Stolina M et al (2000) Intratumoral administration of adenoviral interleukin 7 gene-modified dendritic cells augments specific antitumor immunity and achieves tumor eradication. Hum Gene Ther 11, 53-65

91. Li B, VanRoey MJ and Jooss K (2007) Recombinant IL-7 
enhances the potency of GM-CSF-secreting tumor cell immunotherapy. Clin Immunol 123, 155-165

92. Pellegrini M, Calzascia T, Elford AR et al (2009) Adjuvant IL-7 antagonizes multiple cellular and molecular inhibitory networks to enhance immunotherapies. Nat Med 15, 528536

93. Andersson A, Srivastava MK, Harris-White M et al (2011) Role of CXCR3 ligands in IL-7/IL-7R alpha-Fc-mediated antitumor activity in lung cancer. Clin Cancer Res 17, 36603672

94. Boyman O, Ramsey C, Kim DM, Sprent J and Surh CD (2008) IL-7/anti-IL-7 mAb complexes restore T cell development and induce homeostatic $\mathrm{T}$ cell expansion without Iymphopenia. J Immunol 180, 7265-7275

95. Martin CE, van Leeuwen EM, Im SJ, Roopenian DC, Sung YC and Surh CD (2013) IL-7/anti-IL-7 mAb complexes augment cytokine potency in mice through association with IgG-Fc and by competition with IL-7R. Blood 121, 4484-4492

96. Nam HJ, Song MY, Choi DH, Yang SH, Jin HT and Sung YC (2010) Marked enhancement of antigen-specific T-cell responses by IL-7-fused nonlytic, but not lytic, Fc as a genetic adjuvant. Eur J Immunol 40, 351-358

97. Lee SW, Choi D, Heo M et al (2020) hIL-7-hyFc, a longacting IL-7, increased absolute lymphocyte count in healthy subjects. Clin Transl Sci 13, 1161-1169

98. Choi YW, Kang MC, Seo YB et al (2016) Intravaginal administration of Fc-fused IL7 suppresses the cervicovaginal tumor by recruiting HPV DNA vaccine-induced CD8 T cells. Clin Cancer Res 22, 5898-5908

99. Kim JH, Kim YM, Choi D et al (2020) Hybrid Fc-fused interleukin-7 induces an inflamed tumor microenvironment and improves the efficacy of cancer immunotherapy. Clin Transl Immunology 9, e1168 